\title{
Determinants of Students' Academic Achievement and Attitude in Mathematics Subject: A Case Study at Gindeberet Preparatory School
}

\author{
Giragn Lemu Beyen ${ }^{1}$, Tesfaye Getahun² \\ ${ }^{1}$ Gindeberet Preparatory School, Gindeberet, Ethiopia \\ ${ }^{2}$ Department of Mathematics, Hawassa University, Hawassa, Ethiopia
}

Email address:

giragnlemu@gmail.com (G. L. Beyen)

To cite this article:

Giragn Lemu Beyen, Tesfaye Getahun. Determinants of Students' Academic Achievement and Attitude in Mathematics Subject: A Case Study at Gindeberet Preparatory School. Education Journal. Vol. 8, No. 4, 2019, pp. 144-154. doi: 10.11648/j.edu.20190804.13

Received: May 11, 2019; Accepted: June 28, 2019; Published: July 24, 2019

\begin{abstract}
Students' academic problem in the achievement of Mathematics education dominates persistently in Gindeberet preparatory school. The insight into the study arose from annual report of school and the researcher's teaching experience. Therefore, the purpose of this study was to identify factors that influence student's achievement towards Mathematics and examine students' attitude towards Mathematics in preparatory school at Gindeberet Woreda. In this study, target population was $1029($ male $=529$ and female=500) of grade 11 students. Simple random sampling technique was used to select the representative from the entire population. Thus, among the total sample (154), 87 were male and 67 were female. Eleven (11) Mathematics teachers were also selected availably. Authors used two data collection instruments; Attitude towards Mathematics Inventory developed by Tapia and Marsh (2004) and questionnaires were employed. Descriptive and inferential statistics were applied for data analysis. The result of this study revealed that, teachers are less committed in teaching methods and strategies that they have used in their lesson were determinants of students' achievement in Mathematics from teachers side and also the students' achievement were determine by parents income, mother educational level, parental involvement, classmate encouragement, time the spent on mathematics task were main statistical significant determinants of students achievement in Mathematics and attitude of students towards Mathematics was neutral in this study. Based on this findings and conclusion valuable recommendations were formed. Thus, based on students attitude towards Mathematics and on others determinants of students achievements in Mathematics; teachers, parents, school administrators, supervisors, communities and other stakeholders should have discussed and work together to improve students success in mathematics cooperatively.
\end{abstract}

Keywords: Determinants, Student Achievement, Preparatory School, Mathematics, Attitude

\section{Introduction}

The socio - economic development of many countries has been strongly linked with education. Several studies showed that researchers have been involved in findings the factors that influence the process of education. Thus, maintaining quality education has been the primary focus of different governments for centuries. With similar principles of other nations, Ethiopia has moved towards globalization and focused to optimized students competence in Mathematics in order to relies on logic, reasoning, problem solving, creativity, and use it as basic and precise language for the other related fields of studies. Hence teaching Mathematics at preparatory school level should given due emphases towards improving students attitude and achievement.

Students' mathematical achievements in secondary school have an influential effect on their performance in college and their future careers. Having a solid background in mathematics helps students develop sophisticated perspectives and offers more career options. The importance of mathematical learning has repeatedly been emphasized by educators and politicians [1]. Both teachers and parents have paid attention to students' performance in mathematics and their progress every year. Politicians have also called for improving students' overall performances and closing students' achievement gaps. Until teachers and parents 
recognize what factors influence the students' mathematics achievement and improvement, they will be unable to help them make substantial academic progress.

Educators have relied on many sources of information and focused on various factors that might affect students' mathematical achievements, including students' own backgrounds, peer environment, and parental involvement [2]. Expertise has confirmed as student's individual characteristics like gender, age, ethnicity, and their family characteristics, marital status, socioeconomic status are significant factors for Mathematics Achievements [3]. Moreover, some interaction effect between the aforementioned factors also investigated [4] where they looked at the interaction of race-ethnicity and gender.

As Gindeberet preparatory school there is also a great problem on student's academic achievement in mathematics. However; especially, for the past two years in Oromia region, West Shoa zone in Gindeberet woreda academic achievements of grade 11 and 12 students in Mathematics was poor. For instance, for grade 12 in 2015 out of 809 only 361 students were scored pass mark. Thus almost $55.37 \%$ of students result in mathematics was score below 50\% in University Entrance examination (UEE). Similarly, in 2016 out of 907355 students were scored pass mark. Thus almost $60.85 \%$ of students result in mathematics was score below $50 \%$ UEE, from annual report of Gindeberet preparatory school (2015-2016), For grade 11 in the past two years most of students were scored between $50 \%$ and $60 \%$ average mark of mathematics test score, from the researcher experience and grade 11 students' mark list (2015-2016).

Therefore, it is essential to identify key factors that affect students' academic achievement in Mathematics in preparatory school at Gindeberet Woreda and give impute to the development of further research that seeks to characterize and understand different variables which may influence students' achievement in mathematics.

\section{Materials and Methods}

\subsection{Target Population}

The study focused only Grade 11 students who were attending their education in 2016/2017. There were 1029 students in Grade11 who attended their education in the preparatory school. From these, the researcher has considered 154 students as a sample.

\subsection{Study Design}

In this study, cross-sectional data were used since the data were collected at one point in the time.

\subsection{Method of Data Collection}

The current study considered both primary and secondary sources. The primary data was collected using a designed questionnaire from sample population. Several literatures explained that survey research collect quantitative, numbered data using mailed questionnaires [5]. Likert- type scales in which respondents are asked to select a response on a point scale, i.e 1 = strongly disagree, $2=$ disagree, $3=$ neutral, $4=$ agree and $5=$ strongly agree are ordinal since the precise difference in magnitude cannot be determined [6]. Therefore, number of designed questionnaire was prepared for teachers and students. Questionnaires were translated from English language to the Oromic language to be able to understand by the students easily. Secondary data was obtained from record office like students' mark list of first semester in 2009/2017.

\subsection{Sampling Techniques and Sample Size Determination}

In this study, simple random sampling technique was used. It is useful when the target population is homogeneous and it is possible to establish strata which are reasonably within each one. There are eleven mathematics teachers at Gindeberet preparatory school. For the survey research, if the population is fewer than 200 individuals, the entire population should be sampled [7]. Moreover, 21 sample students were participated in pilot study. They were drawn from the population using the lottery random sampling method. Participants that makeup pilot sample are usually chosen at random and also they couldn't include in pilot study were not participated in the total sample of 154 respondents in this study [7].

\subsection{Study Variables}

\subsubsection{Dependent Variable}

Student's recorded mark which was evaluated from $100 \%$.

\subsubsection{Independent Variable}

Demographic and socio - economic status of students have considered as independent variables of the study.

\subsection{Method of Data Analysis}

The collected data was entered into SPSS software and analyzed using descriptive statistics, t-test, ANOVA, and regression analysis.

\subsubsection{Multiple Linear Regression Model}

The multiple linear regression model for a response variable, Y, with observed values, $y_{1}, y_{2}, \ldots, y_{n}$ i.e. students Mathematics score, where $n$ is the sample size and $p$ explanatory variables, $X_{1}, X_{2}, \ldots, X_{p}$ with observed values, $x_{1 i}, x_{2 i} \ldots, x_{p i}, i=1, \ldots, n$, is given as:

$$
Y_{i}=\beta_{0}+\beta_{1} X_{1 i}+\beta_{2} X_{2 i}+\ldots+\beta_{p} X_{p i}+\varepsilon_{i} .
$$

where, $\beta_{0}$ is intercept

$\beta_{1}$ to $\beta_{p}$ are slope or coefficient for a given independent variable.

$\varepsilon$ is error term for individual $i$.

Hypothesis Testing for the Overall Significance of Regression Model (ANOVA):

$H_{0}: \beta_{1}=\cdots=\beta_{p}=0$, all of the independent variables are not important or their effect is not significant.

$H_{1}$ : at leaston $\beta_{i} \neq 0$, there is at least one independent variable that can determine the variation of the dependent variable. 
Test Statistics:

$$
\mathrm{F}_{\text {Cal }}=\frac{\text { (RegressionMeanSquare })}{(\text { ResidualMeanSquare })}=\frac{\mathrm{SSR} / \mathrm{K}}{\operatorname{SSE} /(\mathrm{n}-\mathrm{k}-1)}
$$

where:

Regression Sum of Squares (SSR) $=\hat{\beta}$ ' $X^{\prime} Y$

Error Sum of Squares (SSE) $=Y^{\prime} Y-\hat{\beta}^{\prime} X^{\prime} Y$

Decision Rule: If the computed F-value is higher than the tabulated F-value with $\mathrm{p}-1$ degree of freedom for regression (numerator degree of freedom) and n-k-1degree of freedom for Residual (denominator degree of freedom) at $\alpha=0.05$ significance level, then we reject $\mathrm{H}_{0}$.

\subsubsection{Parameter Estimation of the Regression Model}

To estimate the parameters, the researcher used least squares estimation technique. The least squares estimate of a vector of linear regression coefficients $\beta$ is given by:

$$
\hat{\beta}=\left(X^{\prime} X\right)^{-1} X^{\prime} y
$$

\subsubsection{Assessments of the Model Fit}

Measure of the goodness of fit of the model is provided by the Coefficient of Determination, R, defined as the explained variation of the response variable.

The value of $R^{2}$ gives the proportion of the variability of the response variable accounted by the explanatory variables. $R$ ranges in value from 0 to 1 and when $R$ approaches to 0 the estimated regression equation explains none of the variation in $\mathrm{Y}$ and when it approaches to 1 that means all points lie on the regression line and the estimated regression equation explains well. Coefficient of determination (adjusted $\mathrm{R}^{2}$ ) was used to interpret the variability. Individual regression coefficients were assessed using t-test statistic given as the ratio of coefficient to standard error of each coefficient. To diagnostic for normality, the researcher used Q-Q plot and histogram. To check the Multicollinearity, the researcher used Variance Inflation Factor (VIF).

\section{Results and Discussion}

\subsection{Reliability Assessment}

Table 1. Reliability Statistics for Total Items.

\begin{tabular}{ll}
\hline Cronbach's Alpha & N of Items \\
\hline 0.83 & 29 \\
\hline
\end{tabular}

Source: Own survey (2017)

The value of Cronbach's Alpha is used to determine the consistency of the measurement. Reliability co-efficients (Cronbach's Alpha) range from 0.00 to 1.00 with higher coefficients indicating higher levels of reliability [8]. Therefore, the researcher has obtained reliability co-efficients (Cronbach's Alpha) which is equal to 0.83 for questionnaire, which indicate the higher reliability of research instruments.

\subsection{Results of Descriptive Statistics}

Table 2 below indicated that, 67(43.5\%) were females and
$87(56.5 \%)$ of respondents were males. First semester mathematics average mark of female and male students were $60.82(\mathrm{SD}=11.87)$ and $67.46(\mathrm{SD}=11.02)$ respectively. This result shows that, boy's average mark seemed better than females. The reason why males are higher achiever than female students is many factor like female are engaged in many activities at home helping their parents and taking care of their siblings and these factors take lots of their studying times. Gender differences in Mathematics Achievement have been documented with boys significantly out performing than girls [9]. Conversely, [10] has reported girls performing better than boys but some researchers, [11] indicated that this trend seems to change in secondary school because girls shows more mathematics anxiety than boys.

In case of the age, majority of respondent $114(74.0 \%)$ were $17-19$ years old, 33(21.4\%) and 7(4.5\%) were below17 years and above 19 years old in respective order. The Mathematics average result of students whose age belong to below 17 years was, 63.18( $\mathrm{SD}=13.79) .65 .45(\mathrm{SD}=10.97)$ and $56.86(\mathrm{SD}=13.75)$ were whose age between $17-19$ years and above 19 years old respectively. This result indicated that, the average mark of students whose age belongs to 17-19 years old was higher than the other students and also the SD of students whose age between $17 \& 19$ was smaller than the others. Hence this implies student's age has impact on achievement. This result concurs with [12] explain their research that the majority graduating high school in the US was between 17-18 years old. Whereas in Ethiopia context students complete preparatory education at age of 19 years.

Regarding residential background of participants, $112(72.7 \%)$ respondent were lived with both father and mother. While $17(11.0 \%)$ respondents were lived with Grandparents. On the other hand, 25(8.1\%) were lived with either father or mother. The mathematics achievement average result of the respondents who lived with both father and mother was, $65.46(\mathrm{SD}=11.47) .62 .83(\mathrm{SD}=13.26)$ and 61.76 $(\mathrm{SD}=12.53)$ were lived with either father or mother and with their Grandparents respectively and also the SD of students who live with their father and mother was smaller than the others. According to this analysis students that were lived with their both father and mother had a good achievements than students that were lived either father or mother and grandparents. There is strong support for hypothesizing that parents status would be a positive factor of mathematics achievement, although the recent studies shown that parent status is a crucial factor in mathematics achievement [13]. The availability of parents for supporting in many ways is important to student's learning. But the level of parental involvement may have a different effect on student's learning. The general belief is that the more time the parents spent with their children regarding school work, the more likely their children will be academically successful. While this notion was tested to be true for elementary students, the difficulty in determining levels of help needed by each student is different for parents of ethnic minority or low social economic status, as they may be less able to determine effective strategies in helping children with their school work. 
Table 2. Cross tabulation of socioeconomic and demographic variables by academic achievement of respondents.

\begin{tabular}{|c|c|c|c|c|c|}
\hline \multirow{2}{*}{ Variables } & \multirow{2}{*}{ Categories } & \multirow{2}{*}{$\mathbf{N}$} & \multirow{2}{*}{$\%$} & \multicolumn{2}{|c|}{ Academic Achievement of Grade 11 students } \\
\hline & & & & Mean & SD \\
\hline \multirow{2}{*}{ Sex } & Female & 67 & 43.5 & 60.82 & 11.87 \\
\hline & Male & 87 & 56.5 & 67.46 & 11.02 \\
\hline \multirow{4}{*}{ Age } & $<17$ years & 33 & 21.4 & 63.18 & 13.79 \\
\hline & $17-19$ years & 114 & 74.0 & 65.45 & 10.97 \\
\hline & $>19$ years & 7 & 4.5 & 56.86 & 13.75 \\
\hline & $<2$ & 33 & 21.4 & 62.67 & 13.52 \\
\hline \multirow[t]{3}{*}{ Family size } & $2-4$ & 53 & 34.4 & 69.83 & 9.26 \\
\hline & $>4$ & 68 & 44.2 & 61.40 & 11.48 \\
\hline & None & 52 & 33.8 & 55.87 & 11.24 \\
\hline \multirow[t]{2}{*}{ Time allotted to study mathematics per a day } & $<1 \mathrm{hr}$ & 76 & 49.4 & 67.78 & 8.67 \\
\hline & $1-2 \mathrm{hrs}$ & 26 & 16.9 & 72.62 & 10.78 \\
\hline \multirow{3}{*}{$\begin{array}{l}\text { Distance you travel from your home to } \\
\text { school }\end{array}$} & $0-2 \mathrm{Km}$ & 133 & 86.4 & 65.20 & 11.47 \\
\hline & $2-4 \mathrm{Km}$ & 21 & 13.6 & 60.62 & 13.54 \\
\hline & Either father or mother & 25 & 8.1 & 62.83 & 13.26 \\
\hline \multirow[t]{4}{*}{ Who raised you? } & Both & 112 & 72.7 & 65.46 & 11.47 \\
\hline & Grand parents & 17 & 11.0 & 61.76 & 12.53 \\
\hline & Illiterate & 1 & 6 & 58.00 & 0 \\
\hline & Elementary & 18 & 11.7 & 58.28 & 11.32 \\
\hline \multirow{4}{*}{ Father educational level } & High school & 50 & 32.5 & 61.34 & 11.36 \\
\hline & Certificate & 30 & 19.5 & 61.33 & 10.69 \\
\hline & Diploma & 23 & 14.9 & 67.87 & 8.26 \\
\hline & Higher ed ${ }^{n}$ & 32 & 20.8 & 74.03 & 10.44 \\
\hline \multirow{6}{*}{ Mother educational level } & Illiterate & 12 & 7.8 & 48.08 & 14.82 \\
\hline & Elementary & 17 & 11.0 & 62.53 & 8.73 \\
\hline & High school & 50 & 32.5 & 62.90 & 8.89 \\
\hline & Certificate & 26 & 16.9 & 62.31 & 10.17 \\
\hline & Diploma & 19 & 12.3 & 66.00 & 7.82 \\
\hline & Higher ed ${ }^{\mathrm{n}}$ & 30 & 19.5 & 76.17 & 9.33 \\
\hline \multirow{4}{*}{ Your family total income per year (by ETB) } & $5000-10,000$ & 21 & 13.6 & 55.1 & 14.10 \\
\hline & $10,000-15,000$ & 90 & 58.4 & 61.7 & 8.41 \\
\hline & $>15,000$ & 43 & 27.9 & 75.1 & 9.40 \\
\hline & Farmer & 81 & 52.6 & 64.88 & 10.99 \\
\hline \multirow{4}{*}{ Father occupation } & Teacher & 4 & 2.6 & 69.00 & 7.65 \\
\hline & Merchant & 27 & 17.5 & 63.00 & 13.43 \\
\hline & Gov't employee & 36 & 23.4 & 66.83 & 11.86 \\
\hline & Other & 6 & 3.9 & 51.00 & 10.00 \\
\hline \multirow{5}{*}{ Mother occupation } & Housewife & 69 & 44.8 & 62.26 & 10.59 \\
\hline & Teacher & 18 & 11.7 & 76.44 & 9.22 \\
\hline & Merchant & 29 & 18.8 & 62.48 & 13.10 \\
\hline & Gov't employee & 37 & 24.0 & 64.84 & 11.14 \\
\hline & Other & 1 & 6 & 61.00 & 0 \\
\hline \multirow{4}{*}{$\begin{array}{l}\text { Do you have any educated brothers or sisters } \\
\text { who are beyond your grade level? } \\
\text { If your answer for question № } 6 \text { is yes, are } \\
\text { they help you? }\end{array}$} & Yes & 111 & 72.1 & 65.59 & 11.52 \\
\hline & No & 43 & 27.9 & 61.93 & 12.31 \\
\hline & Yes & 98 & 63.6 & 65.69 & 11.85 \\
\hline & No & 13 & 8.4 & 64.85 & 9.00 \\
\hline
\end{tabular}

From Table 2. below, 1(6\%) were students whose fathers are illiterate and their average score was, $58(\mathrm{SD}=0)$. $18(11.7 \%)$, those students who have father who completed elementary education and their average score was 58.28( $\mathrm{SD}=11.32)$. 50(32.5\%), were students whom fathers have completed secondary education and their average score was $61.34(\mathrm{SD}=11.36)$. 30(19.5\%) were students whom fathers have certificate and their average was, 61.33( $\mathrm{SD}=10.69)$. 23(14.9\%) were students whom father have diploma and their average score was, $67.87(\mathrm{SD}=8.26)$. $32(20.8 \%)$ were students whom father graduated from higher education and their average score was, 74.03( $\mathrm{SD}=10.44)$. Even though, this result indicated that students having father who are graduated from higher education achieve greater than others. In addition, $12(7.8 \%)$ were students whose mother are illiterate and their average score was, 48.08( $\mathrm{SD}=14.82)$. 17(11.0\%), were students who have mother who completed elementary education and their average score was $62.53(\mathrm{SD}=8.73) . \quad 50(32.5 \%)$, were students whom mother have completed secondary education and their average score was $62.90(\mathrm{SD}=8.89)$. 26(16.9\%) were students whom mother have certificate and their average was, 62.31(SD=10.17). 19(12.3\%) were students whom mother have diploma and their average score was 66 $(\mathrm{SD}=7.82)$. 30(19.5\%) were students whom mother graduated from higher education and their average score was, $76.17(\mathrm{SD}=9.33)$. Even, the average score of students whom their mother graduated from higher education have variation they were achieving greater than others.

The study is line with [14], children whose parents are of 
high educational levels have better chance of participating in secondary education. Also, parents with high level of education greatly enhanced students' academic achievement. From this study, low level parents' education is negatively influences academic achievement of their children. It is more evident that, parents' education and encouragement are strongly related to improved students' academic performance.

Moreover, 21(13.6\%) were students with their parents yearly income 5,000-10,000 birr and their average was 55.1( $\mathrm{SD}=14.10) .90(58.4 \%)$, were students with their parents yearly income $10,000-15,000$ birr and their average mean was $61.7(\mathrm{SD}=8.41) .43(27.9 \%)$, were students with their parents yearly income $>15,000$ birr and their average was $75.1(\mathrm{SD}=9.40)$. Thus, we can conclude that parents whose income is $>15,000$ per a year, students who belong to this group achieved relatively maximum result in mathematics. But in accordance with their SD, the achievement of students whose parent income is $10000-15000(\mathrm{SD}=8.41)$ is more consistent than that of students parents yearly income $>15,000$. Generally, this implies that when the average parents income increases, the students' academic achievement also increase. Socio-economic status is a critical issue in many African communities where illiteracy and poverty level are high, thus limiting parental involvement in homework [15]. In some cases learning and reference materials have to be shared among some pupils and not all parents are able to buy for their children personal subjectspecific text copies. More important is the fact that some parents expect the children to helps them after school, during the time the children are expected to undertake their homework assignments.

Education usually entails expenses such as buying reading materials, stationery among others. This introduces the element of family economic status into question. As a result studies have noted that economic status determine the extent of parental involvement in their children's education. Parents with high professional qualifications earn high incomes and hence enjoy high economic status.

As Table 2 shows, 81(52.6\%) are students whom their fathers occupation is farming and their average score was, 64.88( $\mathrm{SD}=10.99) . \quad 4(2.6 \%)$ are students having fathers working as a teacher and their average score was, $69(\mathrm{SD}=7.65) .27(17.5 \%)$ are students having fathers working as a merchant and their average score was, 63( $\mathrm{SD}=13.43)$. $36(23.4 \%)$ are students with father working as a government employed and their average score was, 66.83 ( $\mathrm{SD}=11.86)$. $6(3.9 \%)$ are students who have got fathers in other kinds of occupation and their average score was, $51(\mathrm{SD}=10)$. This result shows that, students from fathers who are teachers have the opportunity to achieve a good result. Again, $69(44.8 \%)$ are students whom their mother occupation is housewife and their average score was, $62.26(\mathrm{SD}=10.59)$. $18(11.7 \%)$ are students having mother working as a teacher and their average score was, $76.44(\mathrm{SD}=9.22) .29(18.8 \%)$ are students having mother working as a merchant and their average score was, $62.48(\mathrm{SD}=13.10) .37(24.0 \%)$ are students with mother working as a government employed and their average score was, $64.84(\mathrm{SD}=11.14) .1(6 \%)$ are students who have got mother in other kinds of occupation and their average score was, $61(\mathrm{SD}=0)$. From this result we can conclude that students whose mother was teacher are more achiever than the other. As David (2014) states that, the poor academic achievement of students is posing a problem to educators and a serious concern to parents. It is revealed that the quality of parents and home backgrounds of a student goes a long way to predict the quality and regularity of the satisfaction and provision of a child's functional survival and academic needs. Poor parental care with gross deprivation of social and economic needs of a child, usually yield poor academic achievement of the child.

In Table 2 below, $111(72.1 \%)$ of respondents have elder brothers/sisters. But only $98(63.6 \%)$ of them were supported by their elders to do more and their result was 65.69 $(\mathrm{SD}=11.85)$. Average mark of students who were not supported by their elders were, $64.85(\mathrm{SD}=9.0)$. From this we conclude that, students who are unable to support from their elders were have the same average score with students who got supports. But SD of students who were not supported by their elders is less than the students who got support. This implies that there is a little variation of average score of supported students. This result consistent with various literatures that potentially identified as encouragement from parents as one of the factors that can affect career interest performance and [17] found that lack of parental participation in education is the main cause of poor performance in mathematics and also indicated that the extent to which parents or other family members are actively engaged in student's education had a positive influence on the student's achievement.

Pertaining to teacher encouragement, 119(77.3\%) respondents who confirmed as they never supported/encouraged their average score was $61.18(\mathrm{SD}=10.17)$ whereas $35(22.7 \%)$ were response rarely and their average score was $76.09(\mathrm{SD}=9.66)$ and also the SD of students whose response rarely was less than the other respondents. From this we can conclude that students who get encourage from their teacher were more achiever than other. Experienced teachers have a richer background of experience to draw from and can contribute insight and ideas to the course of teaching and learning, are open to correction and are less dictatorial in classroom [18]. Teachers' experience and student achievement was that students taught by more experienced teachers achieve at a higher level, because their teachers have mastered the content and acquired classroom management skills to deal with different types of classroom problems. Furthermore, more experienced teachers are considered to be more able to concentrate on the most appropriate way to teach particular topics to students who differ in their abilities, prior knowledge and backgrounds.

The respondents who got interested teacher to do difficult problem were score high mathematics achievement than the other. Their average score was 69.44 ( $\mathrm{SD}=9.45)$. Motivating students to be receptive is one of the most important aspects 
of mathematics instruction and a creative aspect of the common core state stand [19]. Thus motivating students is one method of teaching mathematics for success of academic achievement of students. Investigations have constantly shown that an emphasis on teaching and learning has positive effects on students learning, including better initial learning, greater retention and an increased likelihood that the ideas will be used in new situations. Important quality of mathematics teacher is to understand and accept interest, need, abilities, difficulties, and the way they can best learn the mathematical concept [20].

Students who attended tutorial class at school, 36(23.4\%) were have $71.69(\mathrm{SD}=8.74)$ average score, whereas students who didn't attend tutorial class at school, have average score 62.40 $(\mathrm{SD}=11.82)$. This indicates that Students who attended tutorial class were high achiever than the others. Tutorial programs have been touted as a means to increase the achievements of low achiever students and promote academic social and emotional, and behavioral growth by providing positive supervision while also offering academic programming [21].

All respondents $154(100 \%)$ were said that the number of student in the class is greater than 80 . This indicates that class size may have positively relationship with students' academic achievement. Moreover, even to manage, above 80 students in a class is very difficult to teach. The class size refers to a number of pupils regularly scheduled to meet in the administrative and instructional unit, known as class or section, usually under the direct guidance of a single teacher [22]. Students who attend smaller classes in the early grades tend to have higher test scores while they are enrolled in those grades than their counterparts who attend larger classes [23].

Half of the respondents $77(50 \%)$ were said "agree" 59 $(38.3 \%)$ were said that "disagree" and $18(11.7 \%)$ were said that "Undecided" on my mathematics teacher has made me feel I have the ability to go on the mathematics. Their average score were $69.56(\mathrm{SD}=9.36), 62.02(\mathrm{SD}=10.80)$ and $51.61(\mathrm{SD}=12.44)$ respectively. When we see the $\mathrm{SD}$, the respondents who were high achiever have less SD than the others. From this we can see that mathematics achievement is high for students who get interested teacher to made interest into them. Teachers' attitude towards their jobs the majority of teachers are dissatisfied in many ways this lead to: poor planning of teaching, poor methodology and technique of teaching, inappropriate use of guidance services, inadequate use of classroom management, poor classroom evaluation/test construction and poor model for learners [18]. Therefore, up-grading teachers' qualification through in training, improving school leadership, effective reward system, providing professional assistance have a positive effect on their attitude towards their jobs, which in turn affects students academic achievement.

Some of the respondents $35(22.7 \%$ ), were agreed on the idea of getting a mathematics teacher to talk to me about mathematics has usually been a problem, whereas $88(57.1 \%)$ were disagreed and the rest were said that undecided. Their average score were $55.74(\mathrm{SD}=11.58), 70.40(\mathrm{SD}=8.59)$ and $58.00(\mathrm{SD}=10.56)$ respectively. When we see the $\mathrm{SD}$, the respondents who were high achiever have less SD than the others. This indicate that the respondents who said disagree were more achieve than the other. This means to talk to students mathematics subject has usually a problem is demoralize the student. Teacher's attitude does have an influence on student achievement [24]. It is, therefore, important and imperative for mathematics teachers to develop positive attitude towards the subject and make Mathematics interesting and appealing to students in order to help them develop a positive attitude towards it. Mathematics teachers ought to create interesting and non-threatening environments in their mathematics classroom and model enthusiasm for the teaching and learning of the subject.

Majority of the respondents $119(77.3 \%)$ were agreed and $35(22.7 \%)$ were disagreed on the idea my classmates have encouraged me to take mathematics at all levels. Their average score were $66.80(\mathrm{SD}=10.47)$ and $57.00(\mathrm{SD}=13.11)$ respectively and also the SD of students who agreed on the idea was less than the other respondents. From this we can conclude that encouragement of classmates to each other has strongly relationship with students' mathematics achievement. Student achievement is effected in many ways by the effects of a peer group. These effects may be members a group interaction in learning, helping each other in their studies, share important information. Influences on student learning in an academic environment can be numerous and contradictory. The interactions among peers are normal and essential part of the learning process that influences the lifelong learning habits of students. Students may learn better when in the company of other strong students. Peer groups have significant impacts on student achievement, depending on the magnitude of peer influences [25].

Moreover, we observed that 34(22.1\%) respondents were said "agree" and $120(77.9 \%)$ were said that "disagree" on my family has strongly encourages me to do well in mathematics. Their average score were $74.91(\mathrm{SD}=8.66)$ and $61.64(\mathrm{SD}=10.94)$ respectively. When we see the $\mathrm{SD}$, the respondents who were high achiever have less SD than the others. From this we can see that parent's involvement can be factor of students' academic achievement. Parental involvement might have differential influence on academic performance of their children. Parental expectations have a greater impact on student's educational outcomes. Parental involvement may include activities like helping children in reading, encouraging them to do their homework independently, monitoring their activities inside the house and outside the four walls of their house, and providing coaching services for improving their learning in different subjects. Parents play a crucial role in both the home and school environments. In general, parental involvement is associated with children's higher achievements in language and mathematics, enrolment in more challenging programs, greater academic persistence, better behavior, better social skills and adaptation to school, better attendance and lower drop-out rates [26]. 


\subsection{Descriptive Statistics for Students' Attitudes Toward Mathematics Scale}

In this study the Attitudes towards Mathematics Inventory (ATMI) which developed by Tapia and Marsh II (2004) was used to collect the data about students' attitudes towards mathematics. ATMI consists of 40-items, 5-points Likert scale ranging from strongly disagree to strongly agree distributed by using exploratory factor analysis into four scales related to attitudes towards mathematics including self-confidence, value, enjoyment, and motivation as shown in Table 4 below. The instrument has a reliability coefficient alpha of 0.97 with standard error of measurement of 5.67. Also, the inventory demonstrates content and constructs validities.

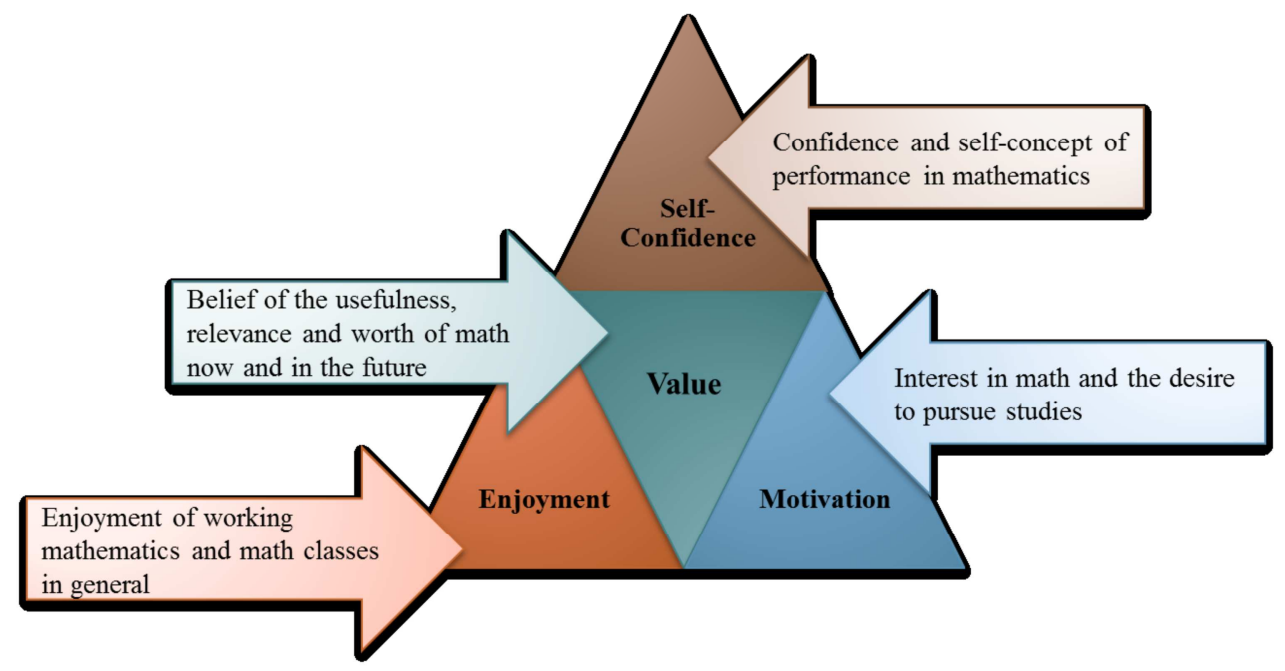

Figure 1. Summary of attitude towards mathematics Scale (ATMS) adopted from [27].

\subsection{Interpretation of Mean Score for ATMS}

Since one of the objective of this study was to identify students' attitude towards mathematics, the interpretation and the decision about their attitude, positive or neutral or negative is given as follows: If ATMS was between 1.00 and 2.33 inclusive interpreted as a student had negative attitude towards mathematics; if it was between 2.34 and 3.66 inclusive interpreted as a student had neutral attitude and if it was between 3.67 and 5.00 inclusive interpreted as a student had positive attitude [31].

\subsection{Data Analysis of the Four Scales}

\subsubsection{Self-Confidence Scale}

Average of the attitude of students in the confidence scales' average of students was $3.12(\mathrm{SD}=0.874)$ which is neutral. This indicated that some students were not confident enough in their performance whereas some of them were have enough self-confident towards mathematics. This result confirm with [28] found that the belief that occasional failure is acceptable in learning mathematics predicts mathematical self-confidence, the practice of allowing children to straggle with challenging problems, even in the elementary grades.

\subsubsection{Value Scale}

Average of the attitude of students in the usefulness of mathematics was $3.18(\mathrm{SD}=0.866)$. From this we can observe that this average value is neutral average value. So this indicated that students had neutral attitude towards the usefulness of mathematics. This result agree with, [29] states that children who develop more Positive competence-related beliefs and values for activities they believe are appropriate for their gender tend to seek more engagement of such activities in the future.

\subsubsection{Enjoyment Scale}

The enjoyment attitude towards mathematics average value of the students was $3.20(\mathrm{SD}=0.873)$ which is neutral average value and it indicated that some students enjoyed doing mathematics whereas some of them were dislike doing mathematics. When students rise to enjoy mathematics lesson, they develop a positive attitudes towards the subject [30]. This eventually leads to high achievement in the subject.

\subsubsection{Motivation Scale}

Motivation scales' average value of students was $3.06(\mathrm{SD}=0.818)$ which is neutral average value. This shows that, some students were not motivated to engage and willing to sustain activities in learning mathematics whereas some of them were motivated. It is obvious that motivation of students towards mathematics is basis for high performance in mathematics. In fact unmotivated students were not done mathematics in advance whereas students who have positive attitude towards mathematics were highly acceptable in improvement of mathematical knowledge. No motivation in students in learning mathematics implies any beliefs to any success for ever. This result related with [28], who found that motivations in mathematics educations are highly individual, are related to perceive ability, and are relatively regard to success and failure.

Moreover, the average score of mean was $3.14(\mathrm{SD}=0.858)$. From this we conclude that, most of the preparatory school students in Gindeberet Woreda had a neutral attitude towards mathematics. 


\subsubsection{Multiple Linear Regression Analysis}

Table 3. Model summary.

\begin{tabular}{|c|c|c|c|c|c|c|c|c|c|}
\hline \multirow{2}{*}{ Model } & \multirow{2}{*}{$\mathbf{R}$} & \multirow{2}{*}{$\mathbf{R}^{2}$} & \multirow{2}{*}{ Adj. $\mathbf{R}^{2}$} & \multirow{2}{*}{ Std. Error } & \multicolumn{5}{|c|}{ Change Statistics } \\
\hline & & & & & $\mathbf{R}^{2}$ & $\mathbf{F}$ & df1 & df2 & Sig. \\
\hline 1 & $.861^{\mathrm{a}}$ & .741 & .720 & 6.253 & .741 & 36.840 & 11 & 142 & .000 \\
\hline
\end{tabular}

The value of adjusted $\mathrm{R}$ Square (0.741) indicates that $74.1 \%$ variation in students' performance is due to the independent variables included in the model.

The $\mathrm{F}$ calculated values with their respective degrees of freedom for the students is $0.000<0.05$ implies that with the confidence $(1-\alpha)$ very close to $100 \%$ one can say that at least one of the coefficients $\beta_{0}$ (where $i=1,2, . .7$ ) is significant for the model. In other words, the variable $\mathrm{Y}$ was better if it was a function of at least one of the variables $\mathrm{X}_{i}$ (where $i=1,2, \ldots, 7$ ) rather than only with $\beta_{0}$. Therefore, the model fit for the data.

Decision: Reject $\mathrm{H}_{\mathrm{o}}$ Since $1-0.000=1>0.95$. Therefore, $\mathrm{X}_{i}$ and $\mathrm{Y}$ are linearly related and that the model fits the data.

Table 4. ANOVA Table.

\begin{tabular}{llllll}
\hline Model & $\begin{array}{l}\text { Sum of } \\
\text { Squares }\end{array}$ & Df & $\begin{array}{l}\text { Mean } \\
\text { Square }\end{array}$ & F & Sig. \\
\hline Regression & 15846.827 & 11 & 1440.621 & 36.840 & $.000^{\mathrm{b}}$ \\
Residual & 5552.887 & 142 & 39.105 & & \\
Total & 21399.714 & 153 & & & \\
\hline
\end{tabular}

Backward stepwise variable selection method was adopted to identify seven dummy variables that determine the score of preparatory school students in grade 11 from originally proposed variables. Variance Inflation Factor (VIF) values corresponding to each independent variable is small (smaller than 10), which indicates that there is no serious Multicollinearity problem. The achievement of students in mathematics is strongly affected by the 7 variables among the 29 variables entered to the regression. These are; my classmates have encouraged me to take mathematics at all levels $(\mathrm{p}=0.000, \beta=2.437)$, getting a mathematics teacher to talk to me about mathematics has usually been a problem $(\mathrm{p}=0.000, \beta=-3.364)$, my mathematics teacher has made me feel I have the ability to go on the mathematics $(\mathrm{p}=0.002, \beta=1.774)$, family total income per year $(\mathrm{p}=0.000$, $\beta=3.949$ ), time allotted to study mathematics per a $\operatorname{day}(\mathrm{p}=0.001, \beta=2.839)$, when we go over our home work, our teacher finds what are had problems with and helps us to overcome these difficulties $(\mathrm{p}=0.000, \beta=4.722)$, and mother educational level $(\mathrm{p}=0.039, \beta=.996)$.

From this analysis of derived data it can be seen that encouragement of their classmates to take mathematics at all level is highly significant as $p$-value $(p=0.000)$ is less than statistically significant level $p=0.05$. From this we can see that as encouragement of their classmates increase by one cycle to increase their mathematics achievement score by 2.437 times. Therefore the null hypothesis, Ho: $\beta_{1}=0$, which there is no statistically significant difference between achievement and encouragement of their classmate is rejected and alternative hypothesis: $\mathrm{H}_{1}: \beta_{1} \neq 0$, in which there is statistically significant difference between student's mathematics achievement and encouragement of their classmate is accepted.

The findings support that of [32], the peer group influence has been of great relevance in students' activities and has resultant significant relationship with their academic performance. This suggests that the group of students related with had positive impact on their academic performance. In the current study, however asserts that peer group could either positively or negatively influences the academic performance in school [33]. Student's interaction with their peer group could influence learning and invariably their academic performance [34]. The probable reason for this significant relationship is that, if students interact with the right peer group that could positively influence their interest to learn, this could invariably motivate them towards their studies and enhance their academic performance. The result of the current study contradicts with some literatures especially from those that investigated students who were bullied by their peers at school tended to report lower levels of self-esteem, feel less connected to peers, teachers and schools were less motivated to perform well at school.

Time allotted to study mathematics is statistically significant to affect student's mathematics achievement, since its $p$-value $(p=0.001)$ is less than statistically significant level $\mathrm{p}=0.05$. This show that as time allotted to study mathematics increase by one cycle to increase their mathematics achievement score by 2.839 times. Therefore the null hypothesis, $\mathrm{H}_{\mathrm{o}}: \beta_{1}=0$, which there is no statistically significant difference between achievement and time allotted to study mathematics rejected and alternative hypothesis, $\mathrm{H}_{1}$ : $\beta_{1} \neq 0$, in which there is statistically significant difference between student's mathematics achievement and time allotted to study mathematics is accepted. The finding is supported [35] states that, time management is related to the academic performance of students. Considering the results related to the number of hours spent daily studying by a student, most of them were as our group had expected, and a few were somehow surprising. As expected, the majority of the successful students study on a daily basis for one to two hours which is, as our group see, reasonable and good enough.

Having a mathematics teacher to talk to students about mathematics has usually been a problem is highly significant as $p$-value $(p=0.000)$ is less than statistically significant level $\mathrm{p}=0.05$. Therefore the null hypothesis, $\mathrm{H}_{\mathrm{o}}: \beta_{1}=0$, which there is no statistically significant difference between achievement and getting a mathematics teacher to talk to students about mathematics has usually been a problem is rejected and alternative hypothesis, $\mathrm{H}_{1}: \beta_{1} \neq 0$, in which there is statistically significant difference between student's mathematics achievement and getting a mathematics teacher 
to talk to students about mathematics has usually been a problem is accepted. Teacher's attitude does have an influence on student achievement [24]. It is, therefore, important and imperative for Mathematics teachers to develop positive attitude towards the subject and make Mathematics interesting and appealing to students in order to help them develop a positive attitude towards it. Mathematics teachers ought to create interesting and non-threatening environments in their Mathematics classroom and model enthusiasm for the teaching and learning of the subject.

Mathematics teacher has made students feel they have the ability to go on the mathematics is statistically significant to affect student's mathematics achievement, since its $p$-value $(p=0.002)$ is less than statistically significant level $p=0.05$. Therefore the null hypothesis, Ho: $\beta_{1}=0$, which there is no statistically significant difference between achievement and mathematics teacher has made students feel they have the ability to go on the mathematics is rejected and alternative hypothesis, $\mathrm{H}_{1}: \beta_{1} \neq 0$, in which there is statistically significant difference between student's mathematics achievement and mathematics teacher has made students feel they have the ability to go on the mathematics is accepted. Motivating students to be receptive is one of the most important aspects of mathematics instruction and a creative aspect of the common core state stand [19]. Thus motivating students is one method of teaching mathematics for success of academic achievement of students. Investigations have constantly shown that an emphasis on teaching and learning has positive effects on students learning, including better initial learning, greater retention and an increased likelihood that the ideas used in new situations [20]. Important quality of mathematics teacher is to understand and accept interest, need, abilities, difficulties, and the way they can best learn the mathematical concept.

Annual parental income is strongly significant as p-value $(\mathrm{p}=0.000)$ is less than statistically significant level $\mathrm{p}=0.05$. Therefore, the null hypothesis, $\mathrm{H}_{0}: \beta_{1}=0$, which there is no statistically significant difference between student's mathematics achievement and parental income is rejected and alternative hypothesis, $\mathrm{H}_{1}: \beta_{1} \neq 0$, in which there is statistically significant difference between student's mathematics achievement and parental income is accepted. [15] Noted that, socio-economic status is a critical issue in many African communities where illiteracy and poverty level are high, thus limiting parental involvement in homework. In some cases learning and reference materials have to be shared among some pupils and not all parents are able to buy for their children personal subject-specific text copies. High poverty levels lead to crowded homes where distractions and little opportunity for concentration is that homework is not guided, poorly done, incomplete or never done at all and therefore precipitates conflicts at school and at home. "Parents of different occupation classes often have different styles of child rearing, different ways of disciplining their children and different ways of reacting to their children. These differences do not express themselves consistently as expected in the case of every family; rather they influence the average tendencies of families for different occupational classes." [36]. Child rearing practices vary with socioeconomic background and parental level of education.

Teacher support while they are doing home work is highly significant as $p$-value $(p=0.000)$ is less than statistically significant level $\mathrm{p}=0.05$. This indicated that as helping of teacher the students to home work increase by one cycle to increase their mathematics achievement score by 4.722 times. Therefore the null hypothesis, $\mathrm{H}_{\mathrm{o}}: \beta_{1}=0$, which there is no statistically significant difference between student's mathematics achievement and teacher help their students when they do home work is rejected and alternative hypothesis, $\mathrm{H}_{1}: \beta_{1} \neq 0$, in which there is statistically significant difference between student's mathematics achievement and teacher help their students when they do home work is accepted. A research by [38] showed that homework can have both positive and negative effects. Cooper reported the positive effects of homework included "improved attitude toward school; better study habits and skills; and learning was encouraged during leisure time; greater self-discipline; better time organization; and more independent problem solving". Cooper also reported significant negative effects of homework as "loss of interest in academic material; copying homework from other students; and getting help beyond tutoring". Research by [39] has shown that the positive effects of homework generally outweigh the negative effects. [39] Suggested that teacher' follow assessment principles in assigning and evaluating home work effectiveness. The homework assignment should be consistent to the overall teaching strategy and assessment for the course. Where homework counted towards final grades, teachers felt students took it more seriously.

Mother educational level is statistically significant to affect student's mathematics achievement, since its $p$-value $(p=0.039)$ is less than statistically significant level $p=0.05$. Therefore the null hypothesis, $\mathrm{H}_{0}: \beta_{1}=0$, which there is no statistically significant difference between achievement and mother educational level is rejected and alternative hypothesis, $\mathrm{H}_{1}: \beta_{1} \neq 0$, in which there is statistically significant difference between student's mathematics achievement and mother educational level is accepted. According to [37] the educational attainment of parents determines the kind of school to which children go to, such schools are near somehow the same to the ones their parents attended. This tends to play a foundation for better performance of their children while at school. [40] In their study in Australia on the influence of education disadvantages in their academic performance of a school found that families where parents are educated foster a high level of achievement in their children because of providing psychological support their children. The evidence about the benefits of parents being involved in their children's education in general and their literacy in school activities in particular, is over whelming.

Hypothesis; $\mathrm{H}_{\mathrm{o}}$ : there are no difference between student's achievement and the predictor

$\mathrm{H}_{1}$ : there is a significant difference between student's achievement and the predictor 
Table 5. Parameter Estimation of Regression Model.

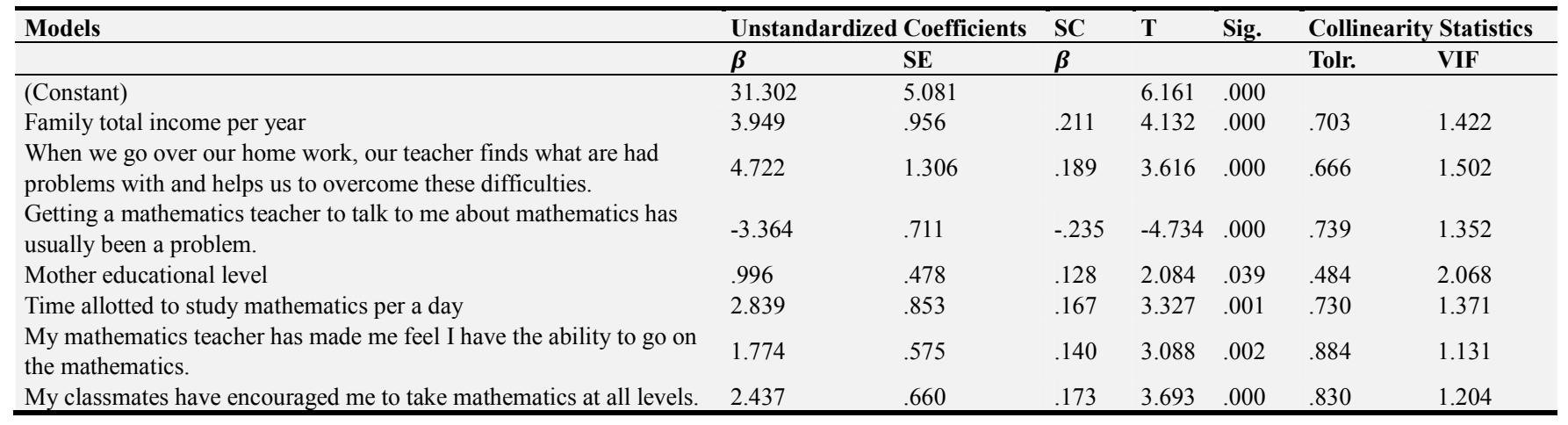

\section{Conclusion}

From the statistical analysis that we have conducted, the following conclusions were drawn.

With this study we found that factors that potentially influences students' academic achievement includes; classmates encouragement, getting a mathematics teacher to talk to students about mathematics has usually been a problem, teacher encouragement, family annual income, time allotted to study mathematics per a day, doing home work and mother educational level. These were among the factors that were statistically significant to influence academic achievement of students in Gindeberet preparatory school. This causes poor academic achievement of students in mathematics subjects in Gindeberet woreda preparatory school. On assessment of preparatory school students' attitude towards mathematics, all of the sample students responses shown mean value between 2.34 \& 3.66 for neutrally phrased statements in the four scales of attitudes. In a situation where such educational research is scarce, research of this kind can contribute to an understanding of why differences occur in academic achievement.

\section{References}

[1] Wilkins, J. L., \& Ma, X. (2002). Predicting student growth in mathematical content knowledge. The Journal of Educational Research, 95, 288-298.

[2] Young, D. J., Reynolds, A. J., \& Walberg, H. J. (1996). Science achievement and educational productivity: A hierarchical linear model. The Journal of Educational Research, 89, 272-278.

[3] Ma, X., \& Klinger, D. A. (2000). Hierarchical Linear Modeling of Student and School Effects on Academic Achievement. Canadian Journal of Education, 25, 41-55.

[4] Muller, P. A., Stage, F. K., \& Kinzie, J. (2001). Science achievement growth trajectories: Understanding factors related to gender and racial-ethnic differences in precollege science achievement. American Education Research Journal. 38, 981-1012.

[5] Cresswell, J. W. (2012). Educational research: Planning, conducting and evaluating quantitative $\&$ qualitative research $\left(4^{\text {th }} \mathrm{ed}\right)$. University of Nebraska- Lincoln.
[6] O'Leary Z, (2004), The essential guide to doing research, sage publications Ltd Cromwell Press, London.

[7] Lodico, G. M., Spaucding, T. D., and Voegtle, H. K. (2010). Methods in Educational Research: From theory to practice. $\left(2^{\text {nd }}\right.$ edition). USA, published by Jossey Bass.

[8] Devils R. F. (2006) Classical test theory.

[9] Kaahwa J 2012. The experience of Ugandan females in Mathematics. Science Journal of Psychology, 2012, Article ID sjpsych-103, 12 pages. doi: 10.7237/sjpsych/103.

[10] Namusisi S (2010). Socio-cultural school based determinants of girl child education: A case of language in universal primary education in Uganda. PhD dissertation. Austria: University of Innsbruck.

[11] Karimi, A., \& Venkatesan, S. (2009). Mathematics anxiety, mathematics performance and academic hardiness in high school students. International Journal of Educational Sciences, 1 (1), 33-37.

[12] Nordin, M. S. et al, (2011). The influence of age and gender on the students' achievement in mathematics; 2011 International Conference on social series and Humanity IPEDR VI 5 (2011) pp 306-307.

[13] Adeyemo, D. A. (2005). Parental Involvement Interest in Schooling and School Environment as predictors of Academic Self-efficacy among fresh Secondary School Student in Oyo State, Nigeria. Electronic Journal of Research in Educational Psychology, 5-3 (1) 163- 180.

[14] Oloo, M. A. (2003). Gender Disparity in Student Performance in day Secondary Schools, Unpublished Master of Education Thesis, Maseno University, Migori, Kenya. 141pp.

[15] Ogoye, H. (2007). Parental participation in pupils' homework in Kenya: In search of an inclusive policy. Nairobi: Act press.

[16] David. M. N (2014), Determinants of poor academic performance of secondary school students in sumbawanga district, Tanzania in rural development of Sokoine university of agriculture. morogoro, Tanzania.

[17] Tota U. S, Ababa, A. and abdullahi. M. S. (2014). the causes of poor performance in mathematics among secondary school.

[18] Zenebe L. (2015) Factors that Affect Students' Academic Achievement in Government Secondary Schools of Asella Town, Oromia National Regional State. in Educational leadership at Haramaya University. 
[19] Airfred, p. (2015). Strategies for motivating students in mathematics. Mathematics education at Mercy college, Newyork.

[20] Douglass, A. G. \& Kristi's, J. G. (2000). Improving student's achievement in mathematics. Brussels: LAE.

[21] Tadiwos Mamo (2015), The attitude and achievement of lower achiever students in the mathematics and mathematics tutorial program; the case of grade 9th students at atse naod school. Addis Ababa University College of Education and Behavioral Studies.

[22] Monere. 2000. Walters Editor, Encyclopedia of educational Research. New York: macmillan company.

[23] Krueger, A. \& Whitmore, D. 2006. Would smaller classes help close the black-white achievement gap? In J. Chubb and T. Loveless, Eds.

[24] Okyere M. and Kuranchie, A (2013) Student attitude towards Mathematics and performance: Does the teacher attitude matter? Faculty of Education, Catholic University College of Education, Fiapre-Sunyani Email of the correspondent author: kuranchiealf@yahoo.com.

[25] Majeed A. (2013). A Confirmatory Factor Analysis of Attitudes Toward Mathematics Inventory (ATMI). I Gusti Ngurah Darmawan Peggy Lynch The University of Adelaide, Australia.

[26] Henderson, A. T., \& Mapp, K. L. 2002. A new wave of evidence: The impact of school, family, and community connections on student achievement. Annual synthesis.

[27] Tapia, M., \& Marsh, G. E., II. (2004). An instrument to measure mathematics attitudes. Academic Exchange Quarterly, 8(2), 16-21.

[28] Middleton, A. J \& Spanians, A. P. (1999). Motivations for achievement in mathematics findings, Generalizations, and Criticisms of the research: Journal for research in mathematics education V 30 No 1, 65-88.

[29] Adeleke, S. M, Binuomote \& Adeyinka, S. F, (2013). Determinants of students' academic performance in financial accounting among senior secondary school level; in Oya state, Nigeria. International Journal of Business and management invention. V2 (5), 48-49.

[30] Wekesa, W. P. (2013), An assessment of Factors Affecting
Students' Performance in Secondary Schools in Kakamega Country, kenya. M sc. Thesis in education in Kenya University.

[31] Mohamed L. \& Wheed H; (2011); Secondary students' attitude towards mathematics in a Selected School of Maldives; Institute of Education International Islamic University Malaysia, International Journal of humanities and social science vol. 1 No 15.

[32] Veronica O. (2016) Peer Group and Parental Support as Correlates of academic Performance of Senior Secondary School Students in South West, Nigeria. European Scientific Journal edition vol. 12, No. 7 ISSN: 1857 - 7881 (Print) e ISSN 1857- 7431.

[33] Tope, O. (2011). The influence of peer group on adolescent's academic performance: A case study of some selected schools in Ogun State. Nigeria: Egobooster Books.

[34] Furlong, M. J., S. (2004). Moving Towards a Unifying Framework for Educational Research and Practice. The California School Psychologist. 8: 99-113. provinces: ASISN journal of social science and humanities. V2 (1), pp 174-180.

[35] Miqdadi et. al (2014) The Relationship between Time Management and the Academic Performance of Students from the Petroleum Institute in Abu Dhabi, the UAE. ASEE 2014 Zone I Conference, April 3-5, 2014, University of Bridgeport, Bridgpeort, CT, USA.

[36] Rothstein, R. (2004). Class and schools: Using social, economic, and educational reform to close the black-white achievement gap. Washington, DC: Economic Policy Institute.

[37] Sentamu, N. P. (2003). School's influence of learning: A case of upper primary schools in Kampala \& Wakiso Districts. Uganda Education Journal, 4, 25-41.

[38] Cooper, H. 1994. Homework research and policy: A review of literature. Research/Practice, 2, 2. Retrieved December 8, 2007, from http://education.umn.edu/CAREI/Reports/ Practice/ Summer94/default.html.

[39] Brahier, D. 2000. Teaching secondary and middle school mathematics. Boston: Allyn.

[40] Considine, G. \& Zappala, G. (2002). Influence of social and economic disadvantage in the academic performance of school students in Australia. Journal of Sociology, (38) 129-148. 